\title{
HXI open A population-based cross-sectional study of the association between facial morphology and cardiometabolic risk factors in adolescence
}

\author{
Jelena Djordjevic, ${ }^{1}$ Debbie A Lawlor, ${ }^{2,3}$ Alexei I Zhurov, ${ }^{1}$ Arshed M Toma, ${ }^{1}$ \\ Rebecca Playle, ${ }^{1}$ Stephen Richmond ${ }^{1}$
}

To cite: Djordjevic J, Lawlor DA, Zhurov Al, et al. A population-based crosssectional study of the association between facial morphology and cardiometabolic risk factors in adolescence. BMJ Open 2013;3:e002910.

doi:10.1136/bmjopen-2013002910

- Prepublication history for this paper are available online. To view these files please visit the journal online (http://dx.doi.org/10.1136/ bmjopen-2013-002910).

Received 19 March 2013 Revised 4 April 2013 Accepted 4 April 2013

This final article is available for use under the terms of the Creative Commons Attribution Non-Commercial 2.0 Licence; see http://bmjopen.bmj.com

\footnotetext{
${ }^{1}$ Department of Applied Clinical Research and Public Health, School of Dentistry, Cardiff University, Cardiff, UK ${ }^{2}$ MRC Centre for Causal Analyses in Translational Epidemiology, University of Bristol, Bristol, UK

${ }^{3}$ School of Social and Community Medicine, University of Bristol, Bristol, UK
}

Correspondence to Dr Jelena Djordjevic; alexmjz@ptt.rs

\begin{abstract}
Objective: To determine whether facial morphology is associated with fasting insulin, glucose and lipids independent of body mass index (BMI) in adolescents.

Design: Population-based cross-sectional study.

Setting: Avon Longitudinal Study of Parents and Children (ALSPAC), South West of England.
\end{abstract}

Participants: From the ALSPAC database of 4747 three-dimensional facial laser scans, collected during a follow-up clinic at the age of 15, 2348 white British adolescents (1127 males and 1221 females) were selected on the basis of complete data on cardiometabolic parameters, BMI and Tanner's pubertal stage.

Main outcome measures: Fasting insulin, glucose and lipids (triglycerides, high-density lipoprotein cholesterol (HDLC) and low-density lipoprotein cholesterol (LDLC)).

Results: On the basis of the collection of $63 \mathrm{x}, \mathrm{y}$ and $z$ coordinates of 21 anthropometric landmarks, 14 facial principal components (PCs) were identified. These components explained $82 \%$ of the variation in facial morphology and were used as exposure variables. With adjustment for age, gender and pubertal stage, seven PCs were associated with fasting insulin, none with glucose, three with triglycerides, three with HDLC and four with LDLC. After additional adjustment for BMI, four PCs remained associated with fasting insulin, one with triglycerides and two with LDLC. None of these associations withstood adjustment for multiple comparisons.

Conclusions: These initial hypotheses generating analyses provide no evidence that facial morphology is importantly related to cardiometabolic outcomes. Further examination might be warranted. Facial morphology assessment may have value in identifying other areas of disease risk.

\section{INTRODUCTION}

Recent technological advancements in imaging methods marked a transition from a two-dimensional to three-dimensional (3D)

\section{ARTICLE SUMMARY}

Article focus

- Three-dimensional imaging opens up a new chapter in investigations of facial morphology. Previous research revealed associations of facial morphology with obesity in adolescents, but whether facial morphology can be used to identify those at future risk of adverse cardiometabolic outcomes is unknown.

\section{Key messages}

- Our results suggest that facial morphology is not strongly or consistently associated with fasting insulin, glucose or lipids, particularly after adjustment for body mass index, in white British adolescents. Facial morphology is therefore unlikely to be useful in identifying white British adolescents at future risk of adverse cardiometabolic outcomes.

- A suggested methodology can be used in future studies to explore the associations between facial parameters and other health outcomes. It might provide valuable insights into how facial morphology can be indicative of health.

Strengths and limitations of this study

- The strengths of this study are a large sample size and the homogeneity of the sample: all participants were of white origin, born and brought up in the same region of the UK. A non-invasive, accurate and reliable method was used for capturing details of facial soft tissue morphology. A comprehensive statistical analysis was undertaken to extract principal components of facial morphology.

- The study has some limitations. First of all, the study is ethnic-specific. Second, a face could not be easily represented as a single exposure due to the complexity of its morphology and the vast amount of data captured by the laser scanning system. Therefore, some data reduction was necessary prior to the analysis. Furthermore, it was not possible to control all the confounding factors in a cross-sectional study design. Since faces of adolescents are still developing, changing their shape and size, future studies might have to investigate the relationship between these changes and cardiometabolic characteristics over time. 
approach in craniofacial research, thus opening a new era. A special emphasis has been placed on the development and application of non-invasive methods to capture the human face accurately and reliably. ${ }^{2}$ Among these, laser surface scanning and stereophotogrammetry have gained wide acceptance of the research community. ${ }^{3}$ So far, a large spectrum of medical disciplines have utilised these methods in the investigations of facial growth, facial dysmorphology, craniofacial identification, as well as the influence of different medical conditions on facial phenotype. ${ }^{4-12}$ Therefore, an exciting opportunity has occurred to explore whether facial characteristics can serve as new diagnostic measures of illnesses.

Childhood obesity is becoming an epidemic health problem. ${ }^{13}$ It is evident from many studies that it is associated with an increased risk of type 2 diabetes and cardiovascular disease later in life. ${ }^{14-16}$ Despite this fact, the relation between obesity and craniofacial development has been rarely investigated. Bimaxillary prognathism (overdeveloped jaws in the sagittal direction) and increased transverse facial dimensions seem to indicate the difference between obese adolescents and their normal-weighted peers. ${ }^{17-19}$ However, the association between metabolic phenotype and facial form has not been addressed previously.

In order to investigate this problem, a large sample and a comprehensive 3D approach to facial measurements are needed. In this cross-sectional study, which can be considered to be hypothesis generating, we examined the associations of facial soft tissue morphology with metabolic phenotype (fasting insulin, glucose, triglycerides, high-density lipoprotein cholesterol (HDLc) and low-density lipoprotein cholesterol (LDLc)) in a large general population cohort of adolescents using an existing database of 3D facial laser scans.

\section{MATERIAL AND METHODS Sample}

We used the data from the Avon Longitudinal Study of Parents and Children (ALSPAC), a UK-based longitudinal birth cohort study designed to explore genetic and environmental influences on health and well-being. ${ }^{20}{ }^{21}$ All pregnant women were eligible to participate in ALSPAC if their estimated delivery date fell between 1 April 1991 and 31 December 1992, inclusive. In total, 14541 pregnant women were recruited, and from these women there were 14676 live-born infants. Since age 7, surviving offspring have been invited to regular follow-up clinics.

The current study was approved by the ALSPAC Law and Ethics Committee and the Local Research Ethics Committee and informed consent was obtained from children and their parents or guardians. The data collected during an annual follow-up clinic at the age of 15 , which was attended by 5235 adolescents, were examined. On that occasion, facial laser scanning was performed, and after a dropout of 488 individuals due to the low quality of the scans or some sort of facial dysmorphology, a database of 4747 individuals (2233 males and 2514 females) was formed. ${ }^{22}$ Out of these, we selected 2348 white adolescents (1127 males and 1221 females), with complete data related to the outcome and confounding variables (see below), as facial laser scans were used to derive exposure variables. The flow chart diagram (figure 1) shows a gradual selection of individuals who comprised the final sample. In order to make sure that there was no selection bias, we first compared facial principal components (PCs; ie, exposure variables; see below) of the study sample (2348 adolescents) with those of 4747 adolescents forming a 3D facial database ${ }^{22}$ and concluded that there was no reason to believe that selected individuals were significantly different in terms of facial morphology. Second, we compared observed values for outcomes and confounding variables in the study sample (2348 adolescents) with imputed variables in the eligible sample of the follow-up clinic (5235 adolescents), which were published as supplementary online material of the previous study. ${ }^{23}$ The distributions in imputed datasets were very similar to those observed, providing some evidence that the missing data were missing at random.

\section{Measures}

\section{Exposure variables}

Facial laser scans were used to derive PCs of facial morphology, which served as the exposure variables. This is explained in detail in the section on statistical analysis. Prior to this, it was necessary to perform three steps, which will be described here. First of all, facial scans were processed. The validity and reliability of the laser scanning procedure, as well as the processing stages of the scans, have been previously investigated. ${ }^{24-}$ ${ }^{27}$ Second, 21 anthropometric landmarks were manually identified on facial scans by one experienced examiner (figure 2), according to their respective definitions by Farkas, ${ }^{28}$ and their $\mathrm{x}, \mathrm{y}$ and $\mathrm{z}$ coordinates were saved for the subsequent analysis. Previous research showed that these landmarks are clinically reliable. ${ }^{29}{ }^{30}$ Finally, facial scans were initially normalised according to the natural head position, with the origin of the coordinate system set at the point halfway between the inner corners of the eyes (mid-endocanthion). The $\mathrm{x}$-axis was pointing left, from the right eye to the left eye, the y-axis was pointing vertically upwards from the chin to the forehead and the z-axis was pointing outwards, in the nose direction. The coronal, sagittal and transverse planes were taken as the xy, yz and xz planes, respectively. ${ }^{1} 282229$

\section{Outcome variables}

Fasting insulin, fasting glucose, triglycerides, HDLc and LDLc were taken as the outcome variables. Full details of their assessment have been previously reported. ${ }^{23}$

\section{Confounding variables}

Since this study is exploratory (being the first to examine these associations) and our main motivation 
Figure 1 Flow chart showing the selection of a study sample from a 15+ year follow-up clinic of the Avon Longitudinal Study of Parents and Children. All analyses presented in this paper are based on 2348 participants with complete data on facial soft tissue morphology (exposure), blood-based indicators of insulin resistance and associated cardiometabolic risk factors (outcomes) and body mass index and pubertal stage (covariables).

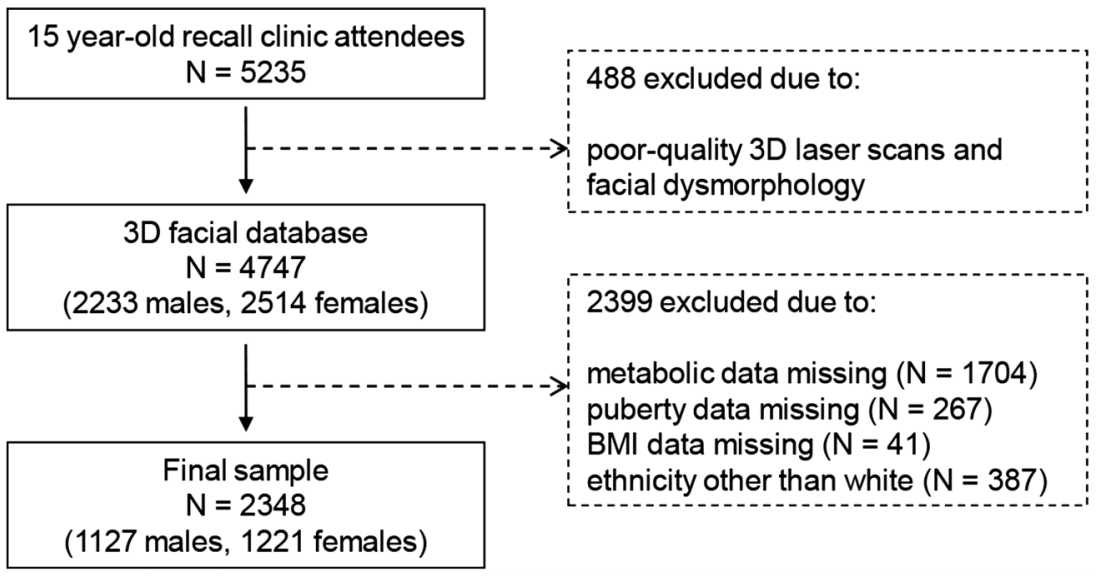

was to understand whether facial morphology might be able to predict those at risk of cardiometabolic disease over and above simple measurement of adiposity, we did not adjust for a wide range of confounding variables. However, we adjusted for age, pubertal stage and body mass index (BMI), as these are potentially important predictors of cardiometabolic risk and we would want to be clear that facial morphology predicted outcome over and above these. The age of the participants was recorded in months as they arrived at the clinic. Pubertal status was assessed on participants' self report with Tanner's questionnaires.

\section{Statistical analyses}

Participant characteristics were summarised with means (SD) for continuous, approximately normally distributed variables, median (IQR) for continuous right skewed variables, and the number (\%) of categorical variables.

Generalised Procrustes Analysis (GPA) was performed on landmark configurations (each consisting of $63 \mathrm{x}, \mathrm{y}$ and $\mathrm{z}$ coordinates of 21 facial landmarks) in order to remove differences in landmark positions attributable to translation and rotation. ${ }^{31-33}$ Scaling was not performed in order to preserve facial size. Principal Component Analysis (PCA) was used to reduce the set of 63 coordinates into a smaller number of independent components of facial morphology. According to the 'Kaiser-Guttman criterion', PCs with eigenvalues greater than the average eigenvalue value were retained ${ }^{34-36}$ and saved as new exposure variables. The rotation method used for PCA was varimax with Kaiser normalisation. ${ }^{37}$ GPA was performed in the open source software $\mathrm{R}$ project and PCA in SPSS V.17.0 (SPSS Inc, Chicago, Illinois, USA).

While this is a cross-sectional study, in all our analyses we examined the association of PCs of facial morphology (as exposures) with fasting insulin, glucose, triglycerides, HDLc and LDLc (as outcomes) using multivariable linear regression models. No evidence was found for any gender interactions (all $p$ values $\geq 0.1$ ), and therefore analyses are presented with both genders combined. In the first model, we adjusted for age, gender and

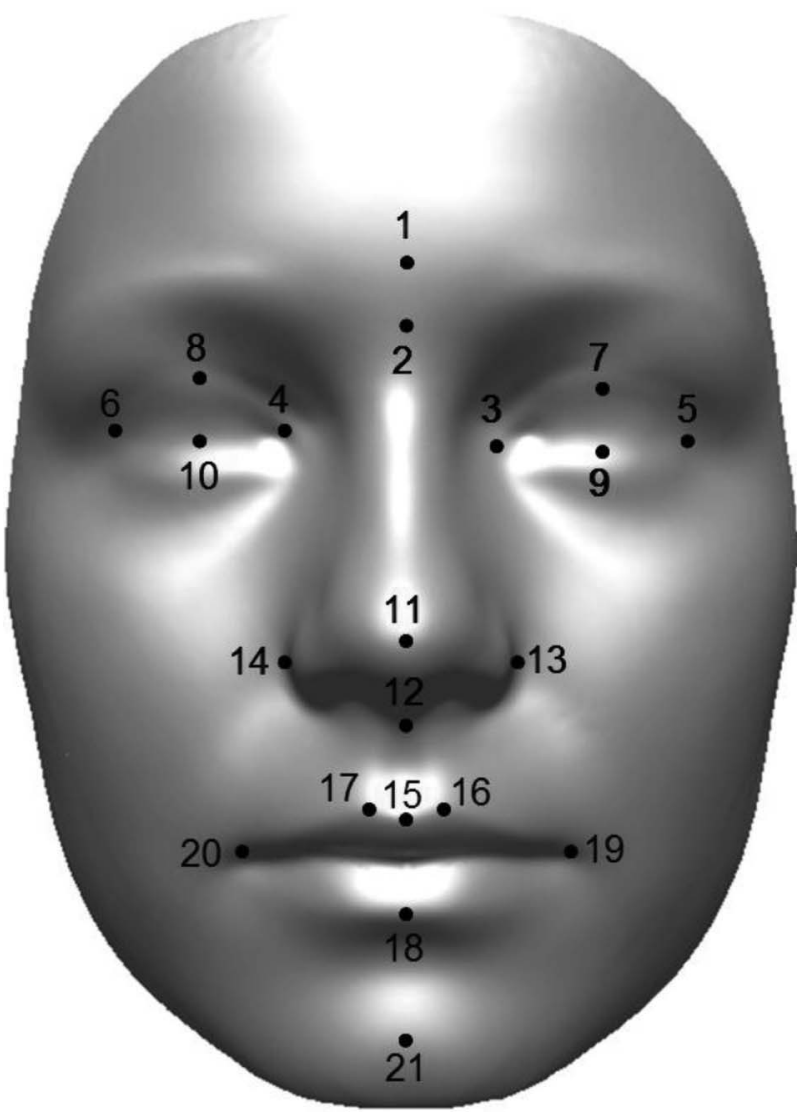

Figure 2 Twenty-one anthropometric landmarks which were identified on facial laser scans of participants. (1) Glabella (g); (2) Nasion (n); (3) Endocanthion left (enl); (4) Endocanthion right (enr); (5) Exocanthion left (exl); (6) Exocanthion right (exr); (7) Palpebrale superius left (psl); (8) Palpebrale superius right (psr); (9) Palpebrale inferius left (pil); (10) Palpebrale inferius right (pir); (11) Pronasale (prn); (12) Subnasale (sn); (13) Alare left (all); (14) Alare right (alr); (15) Labiale superius (Is); (16) Crista philtri left (cphl); (17) Crista philtri right (cphr); (18) Labiale inferius (li); (19) Cheilion left (chl); (20) Cheilion right (chr); (21) Pogonion (pg). Definitions by Farkas ${ }^{28}$ were used. Reprinted from the author's previous publication with permission from 'John Wiley and Sons'. 
pubertal stage. In the second model, we adjusted for age, gender, pubertal stage and BMI and examined how much this reduced any associations of facial PCs with the outcomes. Fasting insulin and triglyceride levels were right (positively) skewed and their logged values were used in the linear regression models, which ensured that the model residuals were approximately normally distributed. The resultant regression coefficients with $95 \% \mathrm{CI}$ are presented.

In these multivariable analyses, 140 comparisons were made (14 exposures with 5 outcomes and 2 models). In initial analyses, we considered the conventional 0.05 level of statistical significance. We then adjusted for multiple comparisons using a Bonferroni correction by dividing 0.05 by 140; thus, for these corrected analyses, a $\mathrm{p}$ value of 0.0004 would be considered to be statistically significant at the 0.05 level. All statistical analyses were performed in SPSS V.17.0 (SPSS Inc).

\section{RESULTS}

Table 1 shows the characteristics of the study participants. The PCA identified 14 PCs of facial morphology (table 2). Each PC consisted of a number of coordinates of anthropometric landmarks. For example, the first PC (PC 1) comprised $17 y$ coordinates of landmarks located in the upper and lower thirds of the face. These coordinates represented facial height (size). In order to facilitate the understanding and interpretation of individual PCs, they are presented graphically in figure 3. The first three PCs (facial size, inter-eye distance and prominence of the nose and lower lip) accounted for almost half of the total variation $(45.7 \%)$. The other 11 PCs contributed to facial variation to a much lesser extent (between 1.6 and $5 \%$ ), but marked those subtle features which make the faces unique.

The multivariable associations of the 14 PCs with cardiometabolic outcomes are shown in tables 3-7. With adjustment for age, gender and pubertal stage (model 1 ), seven PCs were associated with fasting insulin, none with fasting glucose, three PCs with triglycerides and HDLc and four PCs with LDLc. After additional adjustment for BMI (model 2), four PCs remained associated with fasting insulin, none with glucose, one with triglycerides, none with HDLc and two with LDLc. However, none of these associations withstood adjustment for multiple comparisons.

\section{DISCUSSION}

Laser surface scanning is a non-invasive technology which enables the accurate and precise analysis of facial morphology. ${ }^{1}{ }^{24-26}$ Owing to its portability, easy application and relatively low cost, this technique is very suitable for epidemiological field studies. The vast amount of data captured by the system (more than 40000 points, each consisting of $\mathrm{x}, \mathrm{y}$ and $\mathrm{z}$ coordinates) is a testimony to the complexity of facial surfaces. For this reason, the face cannot be easily represented as a single exposure.

Therefore, it was necessary to make some facial data-reduction prior to its meaningful use. First of all,

\begin{tabular}{|c|c|c|c|}
\hline Categories/units & Males $\mathrm{N}=1127$ & Females $\mathrm{N}=1221$ & All $\mathrm{N}=2348$ \\
\hline \multicolumn{4}{|l|}{ Age } \\
\hline Mean (months) & $184.8(3.0)$ & 184.9 (3.2) & $184.9(3.1)$ \\
\hline \multicolumn{4}{|c|}{ Tanner's pubertal stages } \\
\hline Stage In (\%) & 0 & 0 & 0 \\
\hline Stage II n (\%) & $8(0.7)$ & $6(0.5)$ & $14(0.6)$ \\
\hline Stage III n (\%) & $64(5.7)$ & $118(9.7)$ & $182(7.8)$ \\
\hline Stage IV n (\%) & $552(49)$ & $632(51.8)$ & 1184 (50.4) \\
\hline Stage V n (\%) & $503(44.6)$ & 465 (38.1) & 968 (41.2) \\
\hline \multicolumn{4}{|l|}{ BMI } \\
\hline Median $\left(\mathrm{kg} / \mathrm{m}^{2}\right)$ & $20.4(18.9,22.3)$ & $21.2(19.5,23.4)$ & $20.8(19.1,23.0)$ \\
\hline \multicolumn{4}{|l|}{ Fasting insulin } \\
\hline Median (IU/I) & $8.2(5.9,10.9)$ & $9.7(7.4,13.0)$ & $9.0(6.6,12.0)$ \\
\hline \multicolumn{4}{|l|}{ Fasting glucose } \\
\hline Mean $(\mathrm{mmol} / \mathrm{l})$ & $5.3(0.4)$ & $5.1(0.3)$ & $5.2(0.4)$ \\
\hline \multicolumn{4}{|l|}{ Total cholesterol } \\
\hline Mean $(\mathrm{mmol} / \mathrm{l})$ & $3.6(0.6)$ & $3.9(0.6)$ & $3.8(0.6)$ \\
\hline \multicolumn{4}{|l|}{ Triglycerides } \\
\hline Median (mmol/l) & $0.7(0.6,1.0)$ & $0.8(0.6,1.0)$ & $0.7(0.6,1.0)$ \\
\hline \multicolumn{4}{|l|}{ HDLC } \\
\hline Mean (mmol/l) & $1.2(0.3)$ & $1.4(0.3)$ & $1.3(0.3)$ \\
\hline \multicolumn{4}{|l|}{ LDLc } \\
\hline Mean (mmol/l) & $2.0(0.5)$ & $2.2(0.6)$ & $2.1(0.6)$ \\
\hline
\end{tabular}


Table 2 The results of the principal component analysis showing partial correlation coefficients between coordinates of anthropometric landmarks and facial principal components

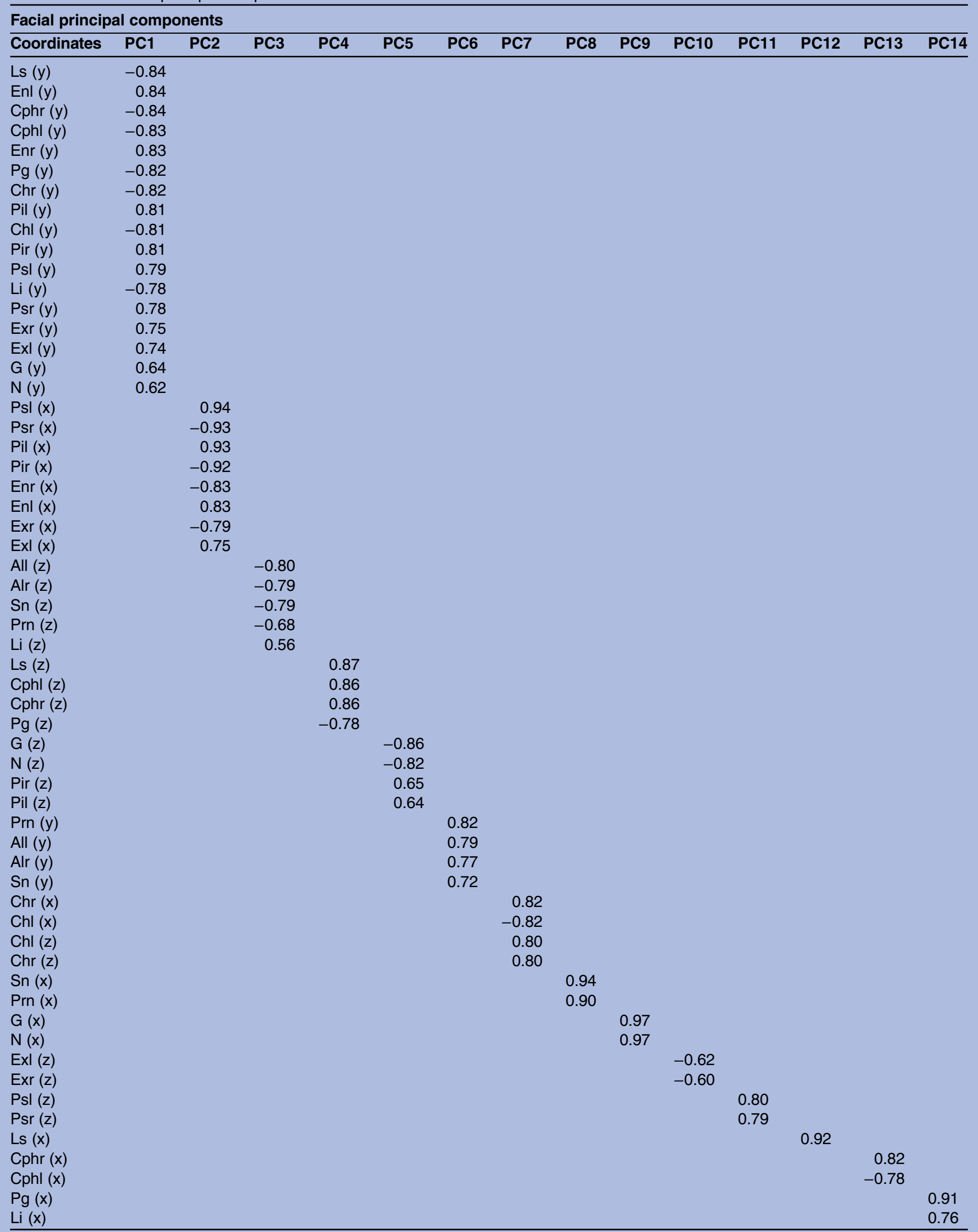




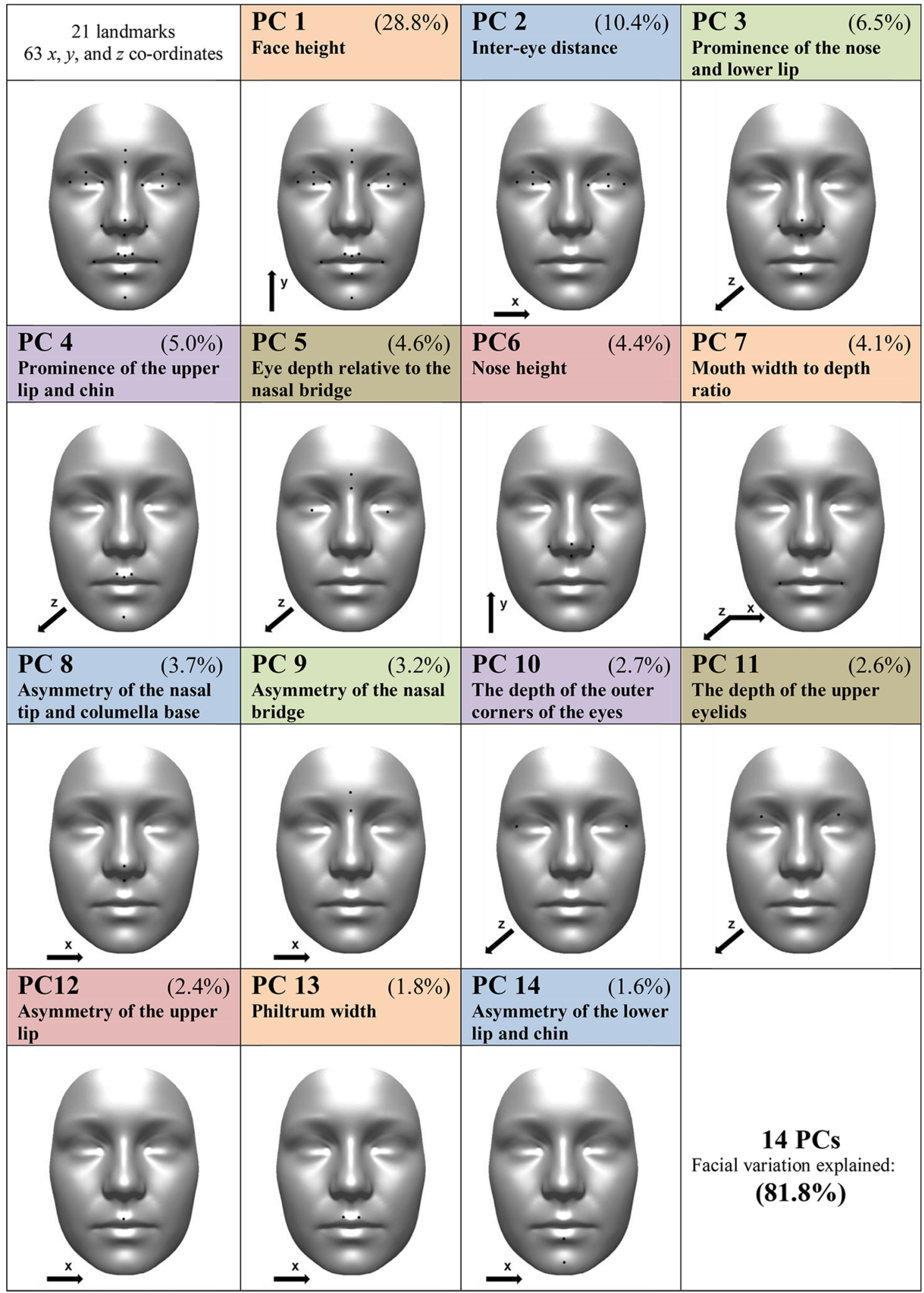

Figure 3 Facial principal components (PCs). Numbers indicate percentages of normal facial variation explained by the given principal component. Coordinates which constitute each principal component are marked on the face (refer to table 2), and arrows indicate the $\mathrm{x}, \mathrm{y}$ and $\mathrm{z}$ directions.

GPA (a widely established method in statistical shape analysis) was used to place landmark coordinates in the same space reducing confounding errors (rotation and translation). Second, PCA was applied on the set of coordinates and 14 facial PCs were identified, which accounted for almost $82 \%$ of the total variation in 
Table 3 Multivariable association of 14 facial principal components (exposures) with fasting insulin as an outcome

\begin{tabular}{|c|c|c|c|c|c|c|}
\hline \multirow[b]{2}{*}{ PC } & \multicolumn{2}{|l|}{ Model 1} & \multirow[b]{2}{*}{ p Value } & \multicolumn{2}{|l|}{ Model 2} & \multirow[b]{2}{*}{ p Value } \\
\hline & B & $(95 \% \mathrm{Cl})$ & & B & $(95 \% \mathrm{Cl})$ & \\
\hline $\mathrm{PC} 1$ & 0.004 & $(-0.006$ to 0.014$)$ & 0.397 & -0.011 & $(-0.021$ to -0.001$)$ & 0.026 \\
\hline PC2 & 0.011 & (0.002 to 0.019$)$ & 0.011 & -0.003 & $(-0.011$ to 0.005$)$ & 0.419 \\
\hline PC3 & 0.010 & (0.002 to 0.019) & 0.015 & 0.002 & $(-0.006$ to 0.010$)$ & 0.681 \\
\hline PC4 & -0.001 & $(-0.009$ to 0.007$)$ & 0.803 & 0.002 & $(-0.005$ to 0.010$)$ & 0.538 \\
\hline PC5 & -0.011 & $(-0.020$ to -0.002$)$ & 0.019 & 0.001 & $(-0.008$ to 0.010$)$ & 0.802 \\
\hline PC6 & 0.010 & (0.002 to 0.018$)$ & 0.013 & 0.001 & $(-0.007$ to 0.009$)$ & 0.787 \\
\hline PC7 & 0.000 & $(-0.008$ to 0.008$)$ & 0.935 & 0.005 & $(-0.003$ to 0.013$)$ & 0.190 \\
\hline PC8 & -0.017 & $(-0.028$ to -0.006$)$ & 0.003 & -0.014 & $(-0.024$ to -0.004$)$ & 0.009 \\
\hline PC9 & 0.012 & $(0.003$ to 0.020$)$ & 0.005 & 0.012 & (0.004 to 0.020$)$ & 0.002 \\
\hline PC10 & 0.005 & $(-0.003$ to 0.014$)$ & 0.190 & 0.002 & $(-0.006$ to 0.010$)$ & 0.601 \\
\hline PC11 & 0.026 & (0.018 to 0.034$)$ & $<0.001$ & 0.009 & (0.001 to 0.017$)$ & 0.029 \\
\hline PC12 & 0.006 & $(-0.002$ to 0.014$)$ & 0.151 & 0.005 & $(-0.002$ to 0.013$)$ & 0.172 \\
\hline PC13 & -0.005 & $(-0.014$ to 0.003$)$ & 0.220 & 0.001 & $(-0.007$ to 0.009$)$ & 0.867 \\
\hline PC14 & -0.003 & $(-0.011$ to 0.005$)$ & 0.485 & -0.005 & $(-0.012$ to 0.003$)$ & 0.236 \\
\hline
\end{tabular}

normal facial form, consisting of size and shape. Normal facial variation was recently analysed on a complete sample of 4747 faces from the ALSPAC database and the same number of PCs was extracted, with an almost identical order of individual PCs and very similar percentages of variation. ${ }^{22}$

The application of this statistical technique is not new. Previously, PCA was performed on two-dimensional data sets, obtained from either lateral skull radiographs or photographs of both children and adults. ${ }^{38-41}$ The resultant number of PCs in these studies was between 6 and 8, and these explained up to $90 \%$ of the total variance in facial profile, based on linear measurements between anthropometric landmarks, or their coordinates. However, with the introduction of sophisticated 3D imaging techniques, the amount of data entering PCA increased significantly. Therefore, the number of PCs which represent facial variation also increased: between 14 and 16 PCs have been reported to account for between $86 \%$ and $92 \%$ of the total variation. ${ }^{10} 114142$

Although the first three components in the current study explain almost half of the total variation, other components are also important, since they represent subtle changes that make the face unique. Therefore, a decision was made to keep all of them in the subsequent multivariable analyses. Following adjustment for BMI

Table 4 Multivariable association of 14 facial principal components (exposures) with fasting glucose as an outcome

\begin{tabular}{|c|c|c|c|c|c|c|}
\hline \multirow[b]{2}{*}{ PC } & \multicolumn{2}{|l|}{ Model 1} & \multirow[b]{2}{*}{ p Value } & \multicolumn{2}{|l|}{ Model 2} & \multirow[b]{2}{*}{ p Value } \\
\hline & $\bar{B}$ & $(95 \% \mathrm{Cl})$ & & $\bar{B}$ & $(95 \% \mathrm{Cl})$ & \\
\hline PC1 & -0.010 & $(-0.028$ to 0.008$)$ & 0.286 & -0.017 & $(-0.035$ to 0.001$)$ & 0.065 \\
\hline PC2 & 0.003 & $(-0.011$ to 0.018$)$ & 0.674 & -0.003 & $(-0.018$ to 0.012$)$ & 0.724 \\
\hline PC3 & 0.010 & $(-0.005$ to 0.025$)$ & 0.197 & 0.006 & $(-0.009$ to 0.021$)$ & 0.458 \\
\hline PC4 & -0.008 & $(-0.023$ to 0.007$)$ & 0.310 & -0.006 & $(-0.021$ to 0.009$)$ & 0.427 \\
\hline PC5 & 0.002 & $(-0.014$ to 0.019$)$ & 0.769 & 0.007 & $(-0.009$ to 0.024$)$ & 0.381 \\
\hline PC6 & 0.012 & $(-0.003$ to 0.026$)$ & 0.115 & 0.009 & $(-0.006$ to 0.023$)$ & 0.243 \\
\hline PC7 & 0.009 & (-0.006 to 0.023$)$ & 0.226 & 0.011 & $(-0.004$ to 0.025$)$ & 0.147 \\
\hline PC8 & -0.002 & $(-0.016$ to 0.013$)$ & 0.808 & -0.001 & $(-0.015$ to 0.014$)$ & 0.924 \\
\hline PC9 & -0.004 & $(-0.018$ to 0.011$)$ & 0.613 & -0.003 & $(-0.018$ to 0.011$)$ & 0.657 \\
\hline PC10 & -0.011 & $(-0.026$ to 0.003$)$ & 0.124 & -0.013 & ( -0.027 to 0.002$)$ & 0.083 \\
\hline PC11 & 0.008 & $(-0.007$ to 0.023$)$ & 0.301 & 0.002 & $(-0.014$ to 0.017$)$ & 0.838 \\
\hline PC12 & 0.005 & $(-0.010$ to 0.019$)$ & 0.535 & 0.005 & $(-0.010$ to 0.019$)$ & 0.521 \\
\hline PC13 & 0.003 & $(-0.013$ to 0.018$)$ & 0.730 & 0.004 & $(-0.011$ to 0.020$)$ & 0.563 \\
\hline PC14 & 0.001 & $(-0.013$ to 0.016$)$ & 0.866 & 0.002 & $(-0.013$ to 0.016$)$ & 0.812 \\
\hline
\end{tabular}

Model 1 is adjusted for age, gender and puberty (adjusted $\mathrm{R}^{2}=0.05$ ); model 2 is adjusted for age, gender, puberty and body mass index (adjusted $\mathrm{R}^{2}=0.06$ ). $\mathrm{PC}$, principal component of the face (refer to the text, table 2 and figure 3 for an explanation); $\mathrm{B}$, regression coefficient. 
Table 5 Multivariable association of 14 facial principal components (exposures) with triglycerides as an outcome

\begin{tabular}{|c|c|c|c|c|c|c|}
\hline \multirow[b]{2}{*}{ PC } & \multicolumn{2}{|l|}{ Model 1} & \multirow[b]{2}{*}{ p Value } & \multicolumn{2}{|c|}{ Model 2} & \multirow[b]{2}{*}{ p Value } \\
\hline & B & $(95 \% \mathrm{Cl})$ & & B & $(95 \% \mathrm{Cl})$ & \\
\hline $\mathrm{PC} 1$ & 0.010 & $(-0.001$ to 0.020$)$ & 0.073 & 0.000 & $(-0.011$ to 0.010$)$ & 0.975 \\
\hline $\mathrm{PC} 2$ & 0.004 & $(-0.003$ to 0.010$)$ & 0.291 & -0.003 & $(-0.010$ to 0.003$)$ & 0.351 \\
\hline PC3 & 0.008 & (0.001 to 0.015$)$ & 0.019 & 0.004 & $(-0.003$ to 0.010$)$ & 0.287 \\
\hline PC4 & -0.005 & (-0.001 to 0.002$)$ & 0.177 & -0.003 & $(-0.009$ to 0.004$)$ & 0.397 \\
\hline PC5 & -0.001 & $(-0.008$ to 0.007$)$ & 0.818 & 0.005 & $(-0.002$ to 0.012$)$ & 0.193 \\
\hline PC6 & 0.011 & (0.004 to 0.017$)$ & 0.001 & 0.007 & (0.000 to 0.013$)$ & 0.045 \\
\hline PC7 & 0.000 & $(-0.007$ to 0.006$)$ & 0.945 & 0.002 & $(-0.005$ to 0.008$)$ & 0.563 \\
\hline PC8 & -0.005 & $(-0.012$ to 0.001$)$ & 0.118 & -0.004 & $(-0.011$ to 0.002$)$ & 0.206 \\
\hline PC9 & 0.005 & $(-0.001$ to 0.012$)$ & 0.113 & 0.006 & $(-0.001$ to 0.012$)$ & 0.086 \\
\hline PC10 & 0.005 & (-0.001 to 0.012$)$ & 0.113 & 0.004 & $(-0.003$ to 0.010$)$ & 0.263 \\
\hline PC11 & 0.008 & (0.001 to 0.014$)$ & 0.024 & $<0.001$ & ( -0.007 to 0.007$)$ & 0.988 \\
\hline PC12 & -0.003 & $(-0.010$ to 0.003$)$ & 0.341 & -0.003 & $(-0.010$ to 0.003$)$ & 0.317 \\
\hline PC13 & -0.004 & (-0.011 to 0.003$)$ & 0.213 & -0.002 & $(-0.009$ to 0.005$)$ & 0.601 \\
\hline PC14 & -0.005 & (-0.011 to 0.002$)$ & 0.143 & -0.005 & $(-0.012$ to 0.001$)$ & 0.118 \\
\hline
\end{tabular}

and taking account of multiple statistical testing, we did not find that any of these PCs were associated with fasting insulin or associated cardiometabolic risk factors, suggesting that facial morphology is unlikely to be a reliable way of predicting young people at future risk of type 2 diabetes or cardiovascular disease. Consistent with other large epidemiological studies conducted in healthy general population samples, we were not able to directly measure insulin resistance using the gold standard euglycaemic hyperinsulinaemic clamp. Fasting insulin has been shown to have modest-to-strong correlations with clamp-assessed insulin resistance (correlation coefficients 0.5-0.9) in children and adolescents. ${ }^{43} 44$
Any measurement error is likely to be non-differential and therefore would be expected to bias results towards the null. Since strong associations of these outcomes with BMI have been shown in ALSPAC, ${ }^{23}$ any associations with a better measure of insulin resistance are unlikely to be stronger than those of BMI.

The study has some limitations. First of all, it is ethnicspecific, and therefore future studies will have to address the research question in different ethnic groups. Second, facial variation can be affected by many different factors. While it is possible to control the age, gender and ethnicity of the sample, environmental factors present a greater challenge, even with a good

Table 6 Multivariable association of 14 facial principal components (exposures) with high-density lipoprotein cholesterol as an outcome

\begin{tabular}{|c|c|c|c|c|c|c|}
\hline \multirow[b]{2}{*}{ PC } & \multicolumn{2}{|l|}{ Model 1} & \multirow[b]{2}{*}{ p Value } & \multicolumn{2}{|l|}{ Model 2} & \multirow[b]{2}{*}{ p Value } \\
\hline & B & $(95 \% \mathrm{Cl})$ & & B & $(95 \% \mathrm{Cl})$ & \\
\hline PC1 & -0.028 & $(-0.042$ to -0.014$)$ & $<0.001$ & -0.013 & $(-0.027$ to 0.001$)$ & 0.073 \\
\hline PC2 & -0.005 & $(-0.017$ to 0.006$)$ & 0.351 & 0.008 & $(-0.003$ to 0.020$)$ & 0.154 \\
\hline PC3 & -0.006 & $(-0.017$ to 0.006$)$ & 0.339 & 0.003 & $(-0.008$ to 0.014$)$ & 0.611 \\
\hline PC4 & 0.007 & $(-0.004$ to 0.019$)$ & 0.228 & 0.004 & $(-0.008$ to 0.015$)$ & 0.538 \\
\hline PC5 & 0.007 & $(-0.006$ to 0.020$)$ & 0.279 & -0.005 & $(-0.018$ to 0.008$)$ & 0.443 \\
\hline PC6 & -0.014 & $(-0.025$ to -0.003$)$ & 0.016 & -0.005 & $(-0.016$ to 0.006$)$ & 0.408 \\
\hline PC7 & 0.003 & $(-0.008$ to 0.015$)$ & 0.570 & -0.001 & $(-0.012$ to 0.010$)$ & 0.797 \\
\hline PC8 & 0.009 & $(-0.003$ to 0.020$)$ & 0.129 & 0.007 & $(-0.004$ to 0.018$)$ & 0.205 \\
\hline PC9 & 0.001 & ( -0.010 to 0.012$)$ & 0.883 & 0.000 & $(-0.011$ to 0.011$)$ & 0.940 \\
\hline PC10 & -0.010 & $(-0.022$ to 0.001$)$ & 0.078 & -0.007 & $(-0.018$ to 0.004$)$ & 0.229 \\
\hline PC11 & -0.022 & $(-0.034$ to -0.011$)$ & $<0.001$ & -0.006 & $(-0.017$ to 0.006$)$ & 0.340 \\
\hline PC12 & 0.005 & $(-0.007$ to 0.016$)$ & 0.413 & 0.005 & $(-0.006$ to 0.016$)$ & 0.348 \\
\hline PC13 & 0.005 & $(-0.007$ to 0.017$)$ & 0.387 & -0.001 & $(-0.012$ to 0.011$)$ & 0.905 \\
\hline PC14 & 0.000 & $(-0.012$ to 0.011$)$ & 0.959 & 0.001 & $(-0.010$ to 0.012$)$ & 0.798 \\
\hline
\end{tabular}

Model 1 is adjusted for age, gender and puberty (adjusted $\mathrm{R}^{2}=0.08$ ); model 2 is adjusted for age, gender, puberty and body mass index (adjusted $\mathrm{R}^{2}=0.13$ ). PC, principal component of the face (refer to the text, table 2 and figure 3 for an explanation); $\mathrm{B}$, regression coefficient. Italics indicate statistically significant associations at the level $p<0.05$ (before Bonferroni corrections). 
Table 7 Multivariable association of 14 facial principal components (exposures) with low-density lipoprotein cholesterol as an outcome

\begin{tabular}{|c|c|c|c|c|c|c|}
\hline \multirow[b]{2}{*}{ PC } & \multicolumn{2}{|l|}{ Model 1} & \multirow[b]{2}{*}{ p Value } & \multicolumn{2}{|l|}{ Model 2} & \multirow[b]{2}{*}{ p Value } \\
\hline & B & $(95 \% \mathrm{Cl})$ & & B & $(95 \% \mathrm{Cl})$ & \\
\hline PC1 & 0.004 & $(-0.023$ to 0.030$)$ & 0.793 & -0.014 & $(-0.041$ to 0.013$)$ & 0.307 \\
\hline PC2 & -0.004 & $(-0.026$ to 0.018$)$ & 0.708 & -0.020 & $(-0.042$ to 0.002$)$ & 0.074 \\
\hline PC3 & 0.038 & (0.016 to 0.061$)$ & 0.001 & 0.028 & (0.006 to 0.050$)$ & 0.013 \\
\hline PC4 & -0.002 & $(-0.025$ to 0.020$)$ & 0.855 & 0.002 & $(-0.020$ to 0.024$)$ & 0.851 \\
\hline PC5 & 0.006 & $(-0.019$ to 0.031$)$ & 0.621 & 0.021 & $(-0.004$ to 0.046$)$ & 0.108 \\
\hline PC6 & 0.027 & (0.005 to 0.049$)$ & 0.014 & 0.016 & $(-0.005$ to 0.038$)$ & 0.140 \\
\hline PC7 & 0.012 & $(-0.009$ to 0.034$)$ & 0.263 & 0.018 & $(-0.004$ to 0.040$)$ & 0.103 \\
\hline PC8 & -0.024 & $(-0.045$ to -0.002$)$ & 0.033 & -0.022 & $(-0.043$ to 0.000$)$ & 0.048 \\
\hline PC9 & -0.014 & $(-0.035$ to 0.008$)$ & 0.222 & -0.013 & $(-0.034$ to 0.008$)$ & 0.235 \\
\hline PC10 & 0.006 & $(-0.015$ to 0.028$)$ & 0.561 & 0.002 & $(-0.019$ to 0.024$)$ & 0.824 \\
\hline PC11 & 0.031 & (0.009 to 0.053$)$ & 0.006 & 0.011 & $(-0.011$ to 0.034$)$ & 0.322 \\
\hline PC12 & 0.021 & $(-0.001$ to 0.043$)$ & 0.056 & 0.020 & $(-0.001$ to 0.042$)$ & 0.061 \\
\hline PC13 & -0.006 & $(-0.029$ to 0.016$)$ & 0.582 & 0.001 & $(-0.022$ to 0.023$)$ & 0.961 \\
\hline PC14 & 0.013 & $(-0.009$ to 0.035$)$ & 0.238 & 0.011 & $(-0.010$ to 0.033$)$ & 0.315 \\
\hline
\end{tabular}

Model 1 is adjusted for age, gender and puberty (adjusted $\mathrm{R}^{2}=0.05$ ); model 2 is adjusted for age, gender, puberty and body mass index (adjusted $\mathrm{R}^{2}=0.06$ ). PC, principal component of the face (refer to the text, table 2 and figure 3 for an explanation); $\mathrm{B}$, regression coefficient. Italics indicate statistically significant associations at the level $p<0.05$ (before Bonferroni corrections).

research strategy, as many of them can be unknown at the time of the study. The face changes throughout life, increasing in size and changing in shape. ${ }^{2} 7$ This holds true for the present sample consisting of 15-year-old adolescents. The cross-sectional design of the study did not allow us to track these changes and analyse their relationship with metabolic phenotype through time. That may be more important than the assessment of variation among individuals and thus should be considered in future studies.

\section{CONCLUSION}

Our results do not provide strong evidence that facial morphology is robustly and importantly associated with cardiometabolic risk factors. The associations identified were not consistent across outcomes, were weak in magnitude, attenuated with adjustment for BMI, and did not withstand correction for multiple statistical testing. Further study of facial parameters with cardiometabolic and/or other health outcomes might provide valuable insights into how facial morphology can be indicative of health.

Acknowledgements We are extremely grateful to all the mothers, their parents and the children who were taking part and to the midwives for their cooperation and help in recruitment. The whole ALSPAC study team comprises interviewers, computer technicians, laboratory technicians, clerical workers, research scientists, volunteers and managers who continue to make the study possible. This study could not have been undertaken without the financial support of the Medical Research Council, the Wellcome Trust, the UK Department of Health, the Department of the Environment, and DfEE, the National Institutes of Health, a variety of medical research charities and commercial companies. The ALSPAC study is part of the WHO initiated European Longitudinal Study of Pregnancy \& Childhood.

Contributors JD, DAL and SR were responsible for the conception and the design of the study. JD and SR initiated the study. JD and AMT collected the data. JD, DAL and RP were responsible for statistical analyses. JD, AMT, AIZ and SR analysed and interpreted the data on facial parameters. JD, DAL and
RP analysed and interpreted the data on metabolic parameters. JD and DAL wrote the first draft of the paper. All authors contributed to and approved the final version of the paper.

Funding The research leading to these results has received funding from the Cardiff University for the assessment of facial morphology and from USA National Institute of Health (NIH): National Institute of Diabetes and Digestive and Kidney Diseases (NIDDK) grant number (R01 DK077659) for the measurement of fasting glucose and insulin. The UK Medical Research Council and Wellcome Trust (092731), together with the University of Bristol, provide core support for the ALSPAC study. DAL works in a centre that receives infrastructure funding from the UK Medical Research Council (G0600705). None of the funders influenced the data analyses or the interpretation of results. The comments made in this paper are those of the authors and not necessarily those of any funders.

Competing interests None.

Ethics approval The study was approved by the ALSPAC Law and Ethics Committee and the Local Research Ethics Committee.

Provenance and peer review Not commissioned; externally peer reviewed. Data sharing statement No additional data are available.

\section{REFERENCES}

1. Kau $\mathrm{CH}$, Richmond $\mathrm{S}$. Three-dimensional imaging for orthodontics and maxillofacial surgery. Ames, IA : Wiley Blackwell, 2010.

2. Huang GJ, Richmond S, Vig KWL. Evidence-based orthodontics. Ames, IA: Wiley Blackwell, 2011.

3. Hammond P, Suttie M. Large-scale objective phenotyping of 3D facial morphology. Hum Mutat 2012;33:817-25.

4. Brons S, van Beusichem ME, Bronkhorst EM, et al. Methods to quantify soft-tissue based facial growth and treatment outcomes in children: a systematic review. PLOS ONE 2012;7:e41898.

5. Hammond P. The use of 3D face shape modelling in dysmorphology. Arch Dis Child 2007;92:1120-6.

6. Richmond S, Zhurov A, Toma A. Three-dimensional facial imaging In: Wilkinson C, Rynn C, eds. Craniofacial identification. Cambridge: Cambridge University Press, 2012:154-65.

7. Richmond S, Al Ali AM, Beldie L, et al. Detailing patient specific modeling to aid clinical decision-making. In: Calvo B, Peña E, eds. Patient-specific computational modeling: 5 (lecture notes in computational vision and biomechanics). Dordrecht: Springer, 2012:105-31. 
8. Ali AA, Richmond $\mathrm{S}$, Popat $\mathrm{H}$, et al. The influence of asthma on face shape: a three-dimensional study. Eur J Orthod. Published Online First: 4 October 2012. doi:10.1093/ejo/cjs067

9. Lee RW, Sutherland K, Chan AS, et al. Relationship between surface facial dimensions and upper airway structures in obstructive sleep apnea. Sleep 2010;33:1249-54.

10. Hennessy RJ, Baldwin PA, Browne DJ, et al. Three-dimensional laser surface imaging and geometric morphometrics resolve frontonasal dysmorphology in schizophrenia. Biol Psychiatry 2007;61:1187-94.

11. Hennessy RJ, Baldwin PA, Browne DJ, et al. Frontonasal dysmorphology in bipolar disorder by 3D laser surface imaging and geometric morphometrics: comparisons with schizophrenia. Schizophr Res 2010;122:63-71.

12. Ferrario VF, Sforza C, Dellavia C. Abnormal variations in the facial soft tissues of adults uremic patients on chronic dialysis. Angle Orthod 2005;75:320-5.

13. Herouvi D, Karanasios E, Karayianni C, et al. Cardiovascular disease in childhood: the role of obesity. Eur J Paediatr. Published Online First: 23 January 2013. doi:10.1007/ s00431-013-1932-8

14. Raitakari OT, Juonala M, Kahonen M, et al. Cardiovascular risk factors in childhood and carotid artery intima-media thickness in adulthood: the cardiovascular risk in young Finns study. JAMA 2003;290:2277-83.

15. Owen CG, Whincup PH, Orfei L, et al. Is body mass index before middle age related to coronary heart disease risk in later life? Evidence from observational studies. Int J Obes (Lond) 2009;33:866-77.

16. Han JC, Lawlor DA, Kimm SYS. Childhood obesity. (Peer reviewed commissioned seminar). Lancet 2010;375:1737-48.

17. Ohrn K, Al-Kahlili B, Huggare J, et al. Craniofacial morphology in obese adolescents. Acta Odontol Scand 2002;60:193-7.

18. Ferrario VF, Dellavia C, Tartaglia GM, et al. Soft tissue facial morphology in obese adolescents: a three-dimensional non-invasive assessment. Angle Orthod 2004;74:37-42.

19. Sadeghianrizi A, Forsberg CM, Marcus C, et al. Craniofacial development in obese adolescents. Eur J Orthod 2005;27:550-5.

20. Boyd A, Golding J, Macleod J, et al. Cohort Profile: The 'Children of the 90s': the index offspring of the Avon Longitudinal Study of Parents and Children (ALSPAC). Int $J$ Epidemiol 2013;42:111-27.

21. Fraser A, Macdonald-Wallis C, Tilling K, et al. Cohort Profile: The Avon Longitudinal Study of Parents and Children: ALSPAC mothers cohort. Int J Epidemiol 2013:42:97-110.

22. Toma AM, Zhurov Al, Playle R, et al. The assessment of facial variation in 4747 British schoolchildren. Eur J Orthod 2012;34:655-64.

23. Lawlor DA, Benfield L, Logue J, et al. Association between general and central adiposity in childhood, and change in these, with cardiovascular risk factors in adolescence: prospective cohort study. BMJ 2010;341:c6224.

24. Kau $\mathrm{CH}$, Zhurov Al, Scheer R, et al. The feasibility of measuring three-dimensional facial morphology in children. Orthod Craniofac Res 2004;7:198-204.
25. Kau $\mathrm{CH}$, Richmond $\mathrm{S}$, Zhurov Al, et al. Reliability of measuring facial morphology with a 3-dimensional laser scanning system. Am J Orthod Dentofacial Orthop 2005;128:424-30.

26. Kovacs L, Zimmermann A, Brockmann G, et al. Accuracy and precision of the three-dimensional assessment of the facial surface using a 3-D laser scanner. IEEE Trans Med Imaging 2006;25:742-54.

27. Zhurov Al, Kau CH, Richmond S. Computer methods for measuring 3D facial morphology. In: Middleton J, Shrive MG, Jones ML, eds. Proceedings of the 6th International Symposium on Computer Methods in Bomechanics \& Biomedical Engineering. Cardiff: First Numerics Ltd, 2005 (CD ROM, paper 151D).

28. Farkas LG. Anthropometry of the head and face. New York: Raven Press, 1994:21-5.

29. Toma AM, Zhurov A, Playle R, et al. Reproducibility of facial soft tissue landmarks on 3D laser-scanned facial images. Orthod Craniofac Res 2009;12:33-42.

30. Djordjevic J, Pirttiniemi P, Harila V, et al. Three-dimensional longitudinal assessment of facial symmetry in adolescents. Eur J Orthod 2013;35:143-51.

31. Bookstein FL. Morphometric tools for landmark data. Cambridge: Cambridge University Press, 1991:256-8.

32. Dryden IL, Mardia KV. Statistical shape analysis. Chichester, UK Wiley, 1998

33. Zelditch ML, Swiderski DL, Sheets HD, et al. Geometric morphometrics for biologists: a primer. New York: Elsevier Academic Press, 2004.

34. Guttman L. Some necessary conditions for common factor analysis. Psychometrika 1954;19:149-61.

35. Cliff N. The eigenvalues-greater-than-one rule and the reliability of components. Psychol Bull 1988;103:276-9.

36. Jackson DA. Stopping rules in principal components analysis: a comparison of heuristical and statistical approaches. Ecology 1993;74:2204-14.

37. Kaiser HF. The varimax criterion for analytic rotation in factor analysis. Psychometrika 1958;23:187-200.

38. Cleall JF, BeGole EA, Chebib FS. Craniofacial morphology: a principal component analysis. Am J Orthod 1979;75:650-66.

39. Halazonetis DJ. Morphometric evaluation of soft tissue profile shape Am J Orthod Dentofacial Orthop 2007;131:481-9.

40. Krey KF, Dannhauer KH. Morphometric analysis of facial profile in adults. J Orofac Orthop 2008;69:424-36.

41. Moss JP. The use of three-dimensional imaging in orthodontics. Eur J Orthod 2006;28:416-25.

42. Hennessy RJ, McLearie S, Kinsella A, et al. Facial surface analysis by $3 \mathrm{D}$ laser scanning and geometric morphometrics in relation to sexual dimorphism in cerebral-craniofacial morphogenesis and cognitive function. J Anat 2005;207:283-95.

43. Gungor N, Saad R, Janosky J, et al. Validation of surrogate estimates of insulin sensitivity and insulin secretion in children and adolescents. J Pediatr 2004;144:47-55.

44. Schwartz B, Jacobs DR Jr, Moran A, et al. Measurement of insulin sensitivity in children: comparison between the euglycemic-hyperinsulinemic clamp and surrogate measures. Diabetes Care 2008;31:783-8. 